\title{
Staphylococcus aureus mediates pyroptosis in bovine mammary epithelial cell via activation of NLRP3 inflammasome
}

\author{
Xiaozhou Wang ${ }^{1}$, Mingchao Liu², Na Geng ${ }^{1}$, Yongzhen Du' , Zhaoming Li' ${ }^{1}$, Xin Gao ${ }^{1}$, Bo Han ${ }^{4}$, \\ Jianzhu Liu ${ }^{1,3^{*}}$ and Yongxia Liu ${ }^{1 *}$ (D)
}

\begin{abstract}
Cell death and inflammation are intimately linked during mastitis due to Staphylococcus aureus (S. aureus). Pyroptosis, a programmed necrosis triggered by gasdermin protein family, often occurs after inflammatory caspase activation. Many pathogens invade host cells and activate cell-intrinsic death mechanisms, including pyroptosis, apoptosis, and necroptosis. We reported that bovine mammary epithelial cells (MAC-T) respond to $S$. aureus by NOD-like receptor protein 3 (NLRP3) inflammasome activation through $\mathrm{K}^{+}$efflux, leading to the recruitment of apoptosis-associated speck-like protein (ASC) and the activation of caspase-1. The activated caspase-1 cleaves gasdermin D (GSDMD) and forms a $\mathrm{N}$-terminal pore forming domain that drives swelling and membrane rupture. Membrane rupture results in the release of the pro-inflammatory cytokines IL-18 and IL-1 $\beta$, which are activated by caspase-1. Can modulate GSDMD activation by NLRP3-dependent caspase-1 activation and then cause pyroptosis of bovine mammary epithelial cells.
\end{abstract}

Keywords: Staphylococcus aureus, bovine mastitis, inflammasome, caspase-1, pyroptosis

\section{Introduction}

Staphylococcus aureus infection of the udder in dairy herds is a major cause of bovine mastitis. Staphylococcus aureus is always an important problem to the dairy industry worldwide because of its contagiousness, pathogenicity, and poor prognosis; it also poses a threat to food safety and public health $[1,2]$. Staphylococcus aureus is widespread in the natural environment of dairy farms; its adhesion and invasion of epithelial cells has made the treatment of mastitis difficult [3]. Sensing of S. aureus in bovine mammary glands involves epithelial cells that trigger a cascade of immunity-related processes to kill or inactivate $S$. aureus [4].

\footnotetext{
*Correspondence: liujz@sdau.edu.cn; liuyongxia@sdau.edu.cn

${ }^{1}$ College of Veterinary Medicine, Shandong Agricultural University, Tai'an 271018, Shandong, China

Full list of author information is available at the end of the article
}

Pyroptosis is an inflammatory form of cell death caused by inflammasomes that can be triggered by a variety of stimuli, including bacterial infection and danger signals [5]. GSDMD of the gasdermin protein family is cleaved by inflammatory caspases and exhibits pore forming activity to drive pyroptosis [6, 7]. Inflammasomes play an important role in innate immunity, among which the NLRP3 inflammasome is the best characterized one; NLRP3 can be activated by bacteria through $\mathrm{K}^{+}$efflux $[8,9]$. NLRP3 inflammasomes is an intracellular supramolecular complex composed of the sensor molecules NLRP3, ASC, and caspase-1 [10]. Upon the activation of inflammasome sensor molecules, ASC oligomerizes, thereby forming ASC specks [11]. Full-length caspase-1 is subsequently recruited to the inflammasome and activated by self-cleavage upon interaction with ASC [12]. Upon activation by inflammasomes, caspase- 1 can cleave pro-inflammatory cytokines IL- $1 \beta$ and IL-18 into mature original author(s) and the source, provide a link to the Creative Commons licence, and indicate if changes were made. The images or other third party material in this article are included in the article's Creative Commons licence, unless indicated otherwise in a credit line to the material. If material is not included in the article's Creative Commons licence and your intended use is not permitted by statutory regulation or exceeds the permitted use, you will need to obtain permission directly from the copyright holder. To view a copy of this licence, visit http://creativecommons.org/licenses/by/4.0/. The Creative Commons Public Domain Dedication waiver (http://creativeco mmons.org/publicdomain/zero/1.0/) applies to the data made available in this article, unless otherwise stated in a credit line to the data. 
forms. Activated caspase- 1 can also cleave GSDMD to form GSDMD-N, which binds to the plasma membrane and generates membrane pores, leading to the release of mature IL-1 $\beta$ and IL-18, cell swelling, and eventually, lysis $[13,14]$.

Pyroptosis may be one of the important mechanisms underlying the pathogenesis of bovine mastitis. In this work, we studied whether $S$. aureus can induce pyroptosis in MAC-T cells and further explored its detailed mechanism.

\section{Materials and methods}

\section{Bacterial strains and culture conditions}

Staphylococcus aureus strain ATCC25178 was isolated from bovine mastitis. First, the bacteria were inoculated at the Luria-Bertani (LB) Agar at $37^{\circ} \mathrm{C}$. After $24 \mathrm{~h}$, a separate colony was randomly selected, placed in LB broth, and placed on a shaker at $200 \mathrm{rpm}$ and $37^{\circ} \mathrm{C}$. After $12 \mathrm{~h}$ of culture, bacterial growth was monitored by measuring the $\mathrm{OD}_{600 \mathrm{~nm}}$.

\section{Cell culture and treatment}

MAC-T cells were cultured at $37{ }^{\circ} \mathrm{C}$ with $5 \% \mathrm{CO}_{2}$ in Dulbecco's modified Eagle's medium (Gibco, USA) supplemented with $10 \%$ fetal bovine serum (FBS, Biological Industries, Israel). When cultured to monolayers, cells were infected at a multiplicity of infection (MOI) of 15 in the culture medium. After $2 \mathrm{~h}$ of infection, infected cells were washed thrice with PBS, incubated in medium containing lysostaphin $(10 \mu \mathrm{g} / \mathrm{mL})$ and gentamicin $(100 \mu \mathrm{g} /$ $\mathrm{mL}$ ) to kill extracellular bacteria for $15 \mathrm{~min}$, and incubated in medium containing gentamicin $(50 \mu \mathrm{g} / \mathrm{mL})$ to limit the extracellular replication of $S$. aureus.

\section{Preparation of antibody and inhibitors}

The GSDMD-N antibody preparation was completed by ABclonal Co., Ltd. (China). Rabbits were immunized with the peptide to obtain serum. The peptide sequence used for antibody preparation is shown in Additional file 1 . Then, the specific antibodies were obtained by affinity purification of the antigen. Caspase-1 inhibitor VX765 and NLRP3 inflammasome inhibitor MCC950 were obtained from Glpbio (USA) and used at final concentrations of 100 and $15 \mu \mathrm{M}$.

\section{Measurement of cytokines and activated caspase-1}

Cytokine levels in cell culture supernatants were determined by ELISAs for bovine IL-1 $\beta$ (Raybiotech, USA) and IL 18 (ABclonal, China). Caspase- 1 activity in MAC-T cells was measured using a commercial Caspase-1 Activity Assay Kit (Abbkine, China). All steps were performed according to the manufacturer's guidelines. This assay was based on the hydrolysis of the peptide substrate
acetyl-Tyr-Val-Ala-Asp p-nitroanilide (Ac-YVAD-pNA) by caspase- 1 , which resulted in the release of the yellow formazan product p-nitroaniline (pNA). After treatment, cells were lysed and harvested. Then, they were incubated at $37^{\circ} \mathrm{C}$ for $2 \mathrm{~h}$ with PNA Ac-YVAD-pNA to produce the yellow formazan product pNA, which can be quantified at $405 \mathrm{~nm}$ by spectrophotometer. Caspase- 1 activity was obtained by determining the amount of pNA in the sample according to the standard curve of pNA.

\section{Cytotoxicity and cell death assays}

For cytotoxicity assays, cells grown on coverslips were treated with $S$. aureus for $4 \mathrm{~h}$. Cytotoxicity was assessed by double staining cells with annexin V-FITC/Propidium iodide (PI, Elabscience, China). Annexin V binding requires media supplemented up to $2 \mathrm{mM} \mathrm{CaCl}_{2}$ and controlled at $\mathrm{pH}$ 7.2-7.5. The LDH (lactate dehydrogenase) assay (Dojindo, Japan) was used to measure cell death by cell culture supernatants.

\section{Immunoblotting}

At the desired time points post infection or stimulation, cells were lysed in RIPA lysis buffer (Ncmbio, China) with protease inhibitors on ice for $10 \mathrm{~min}$. The cells were then centrifuged at $12000 \times g$ for $10 \mathrm{~min}$, and the supernatant was obtained and then denatured in 1X Laemmli Buffer with $5 \% \beta$-mercaptoethanol. Proteins were separated by $10 \%-15 \%$ SDS-PAGE gel and transferred to PVDF membranes (Merck Millipore, USA). Then, they were blocked with PBST and 5\% skim milk for $1 \mathrm{~h}$ at RT. After washing with PBST, the membranes were incubated overnight at $4{ }^{\circ} \mathrm{C}$ with mouse anti-Caspase-1 (22915-1-AP, Proteintech, USA), rabbit anti-GSDMD (DF12275, Affbiotech, China), rabbit anti-IL-1 $\beta$ (GTX55675, GeneTex, USA), or mouse anti- $\beta$-actin (66009-1-Ig, Proteintech, USA). After washing with PBST, membranes were incubated with HRP-conjugated secondary antibodies. Proteins were visualized with ECL detection kit (Clinx, China).

\section{Fluorescence and confocal microscopy}

To examine the ASC speck formation or GSDMD-N aggregation on the cell membrane, MAC-T cells grown on coverslips were treated with or without $S$. aureus for $4 \mathrm{~h}$, fixed in $4 \%$ paraformaldehyde, permeabilized with Triton X-100, and blocked with 10\% BSA. Subsequently cells were incubated with antibodies against ASC (105001-AP, Proteintech, USA), GSDMD (DF12275, Affbiotech, China) or GSDMD-N and stained with Alexa Fluor ${ }^{\circledR} 488$ or Alexa Fluor ${ }^{\circledR} 647$ secondary antibody. Nuclei were stained with Hoechst 33342 (Beyotime, China). 


\section{Statistical analysis}

Each experiment was independently repeated at least thrice. Experimental data were analyzed using GraphPad Prism 8. The statistical significance of differences between groups were analyzed by one-way ANOVA with Dunnett's multiple comparison test. $P$ values of less than 0.05 were considered significant and designated by: ${ }^{*} P<0.05,{ }^{* * *} P<0.01$.

\section{Results}

\section{Staphylococcus aureus induces GSDMD cleavage to drive pyroptosis}

GSDMD is a pyroptosis effector downstream of caspase activation; GSDMD-N is an executor of pyroptosis [15]. To determine whether GSDMD is involved in $S$. aureus-induced cell death, we stimulated MAC-T cells with $S$. aureus and examined the active cleavage products of GSDMD in cell lysates. GSDMD was cleaved upon stimulation by $S$. aureus (Figure 1A). Cell death was presented as the percentage of the LDH measured in the culture medium (Figure 1B). GSDMD uniformly distributed in cytoplasm in the absence of $S$. aureus stimulation. GSDMD-N was translocated and accumulated in the plasma membrane after $2 \mathrm{~h}$ of $S$. aureus stimulation as pyroptosis progressed (Figure 1C).

\section{S. aureus-driven pyroptosis by morphology}

Pyroptosis is a necrotic form of cell death, in which cell membranes rupture during pyroptosis [16]. Annexin $\mathrm{V}$ interacts with the phospholipid phosphatidylserine (PS), and when phosphatidylserine is translocated to the outer leaflet of the plasma membrane, annexin $\mathrm{V}$ binds to it and stains it. Considering that pyroptotic cells also have ruptured membranes, annexin $\mathrm{V}$ also stains the plasma membrane. PI is a DNA dye that does not permeate cell membranes, and DNA can be stained by PI after cell membrane rupture. As shown in Figure 2A, cells were markedly swollen, and characteristic large bubbles
A

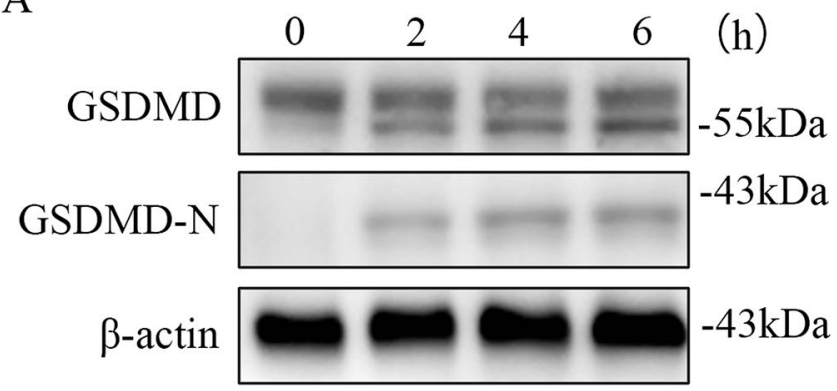

C
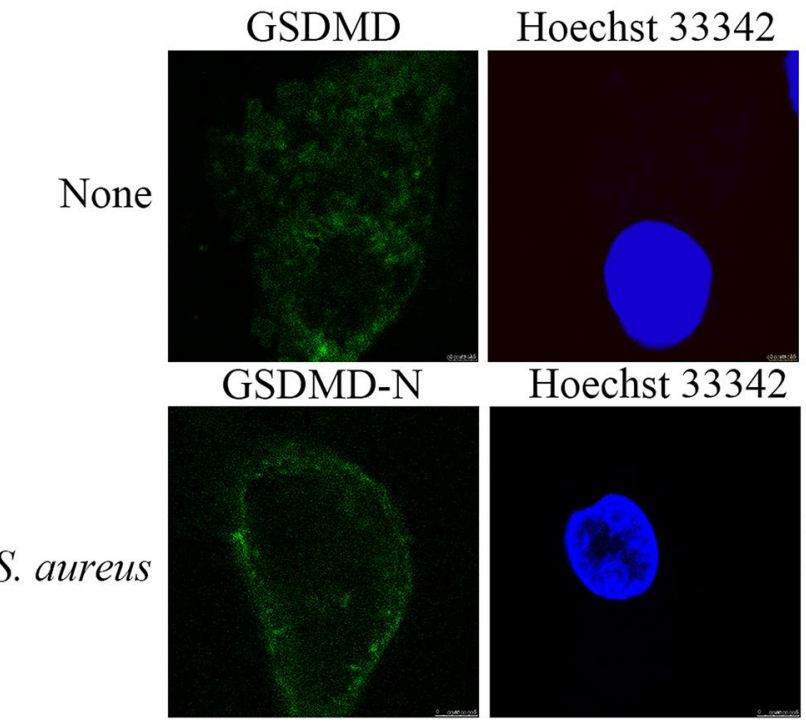

B

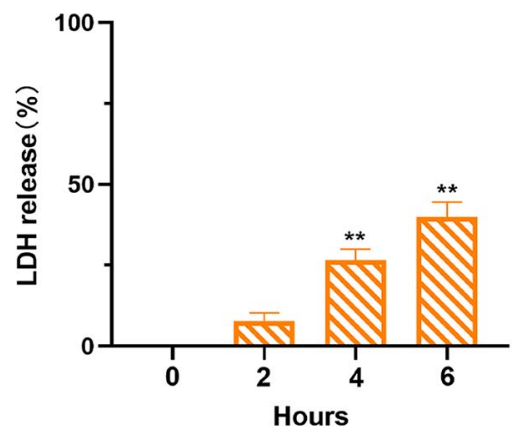

Merge

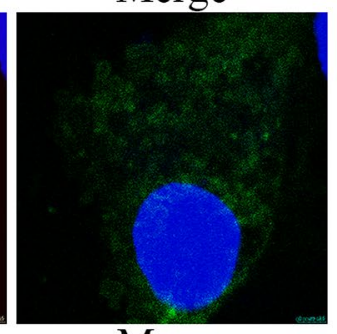

Merge
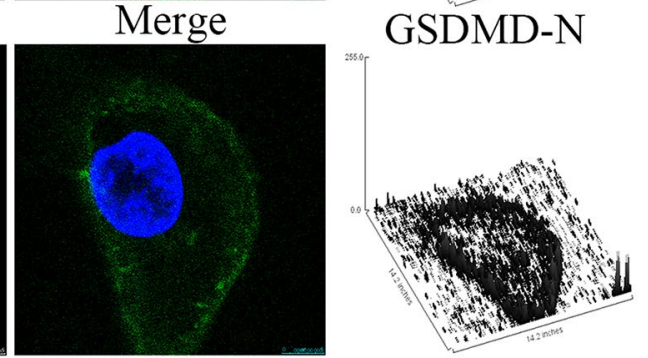

Figure 1 GSDMD activation by S. aureus. A MAC-T cells were treated with S. aureus for the indicated times. GSDMD and GSDMD-N were detected by immunoblotting. B Cell death was measured by LDH release. C Subcellular localization of GSDMD-N or GSDMD in MAC-T cells incubated with or without S. aureus. 


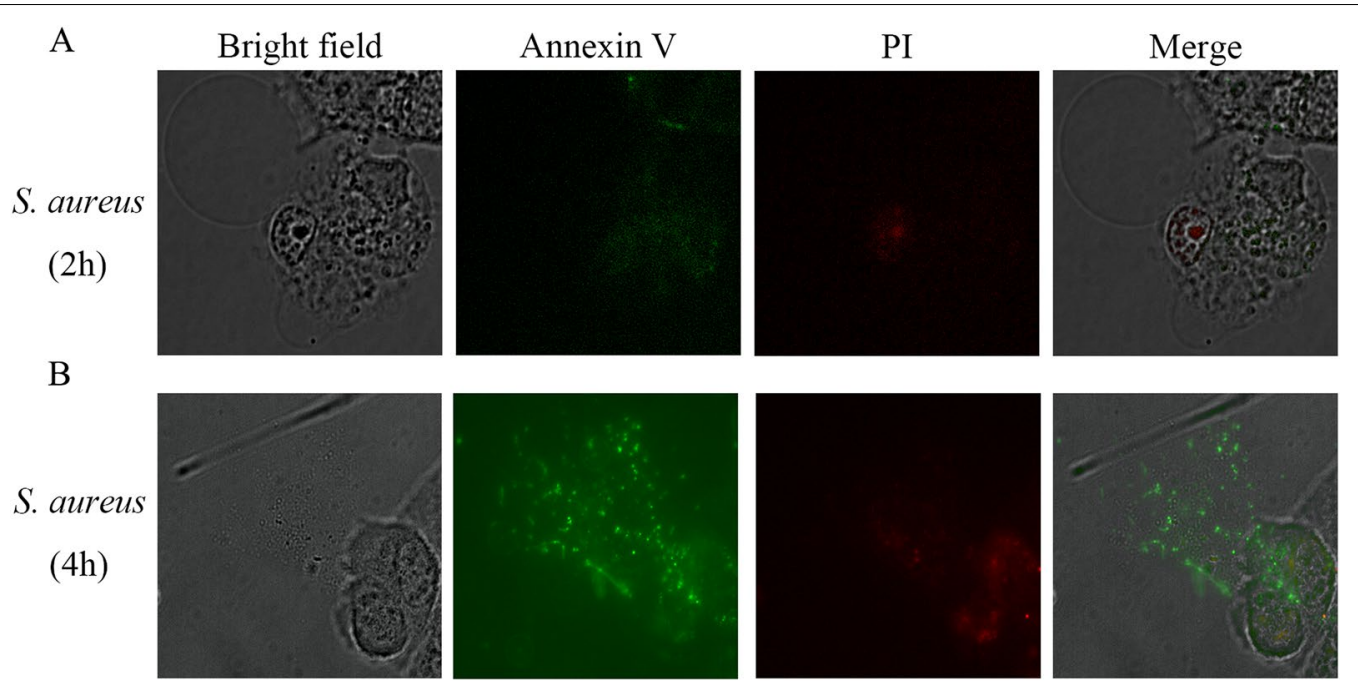

Figure 2 Staphylococcus aureus driven cell death resembles pyroptosis by morphology. A Fluorescence microscopy images of cells stained with annexin $\mathrm{V}$ and $\mathrm{PI}$ in MAC-T cells treated with $\mathrm{S}$. aureus for $2 \mathrm{~h}$ and $\mathbf{B} 4 \mathrm{~h}$.

appeared in the plasma membrane; these are among the typical features of pyroptosis [17]. Membrane disruption and PI signaling were observed in MAC-T cells infected with $\mathrm{S}$. aureus for $4 \mathrm{~h}$ (Figure $2 \mathrm{~B}$ ).

\section{Staphylococcus aureus activates caspase- 1 and induces the release of IL- $1 \beta$ and IL-18}

During pyroptosis, inflammasomes can cleave pro-caspase-1 to generate cleaved caspase-1. Cleaved caspase-1 can directly cleave GSDMD to generate GSDMD-N and can also cleave pro-IL-1 $\beta$ and pro-IL-18 to produce the mature cytokines IL-1 $\beta$ and IL-18. The mature IL-1 $\beta$ and IL-18 are subsequently released from the plasma membrane pores formed by GSDMD-N [18]. The release of IL- $1 \beta$ and IL-18 depends on caspase-1-mediated cleavage. Thus, we measured caspase- 1 activity in MAC-T supernatants (Figure 3A). Results of immunoblotting experiments showed that after $S$. aureus infection of MAC-T cells, the expressions of cleaved caspase- 1 and pro-IL- $1 \beta$ began to increase (Figures $3 B$ and $C$ ). In time course experiments, secretions of IL- $1 \beta$ and IL- 18 by MAC-T cells were detected as early as $4 \mathrm{~h}$ after treatment with S. aureus (Figures 3D and E).

\section{ASC speck formation mediated by NLRP3}

In addition to caspase-1 cleavage secretions of IL-18 and IL-1 $\beta$, another marker of inflammasome activation is the formation of ASC specks. ASC specks were observed after $S$. aureus infection of MAC-T cells. ASC specks were significantly reduced when the cells were pretreated with the NLRP3 inhibitor MCC950 (Figure 4). Upon inflammasome activation, ASC is activated by NLRP3.
Activated ASC is recruited from the nucleus to the cytoplasm and aggregates to form specks, which can be visualized by immunofluorescence microscopy [10, 11].

\section{NLRP3 inflammasomes and caspase-1 are essential for $S$. aureus-mediated release of IL- $1 \beta$ and IL-18 from MAC-T cells}

To assess the role of NLRP3 and caspase-1 in the cleavage of GSDMD caused by $S$. aureus, we pretreated cells with the NLRP3 inhibitor MCC950 or the caspase-1 inhibitor VX765. Inhibition of NLRP3 or caspase-1 in MAC-T cells reduced the activity of caspase- 1 induced by $S$. aureus. GSDMD-N expression was also suppressed (Figures 5A and B). IL-1 $\beta$ and IL-18 release caused by S. aureus was significantly reduced when the cells were pretreated with MCC950 or VX765 (Figures 5C and D). To assess whether the induction of NLRP3 inflammasome activation by $S$. aureus was dependent on $\mathrm{K}^{+}$efflux, MAC-T cells were pretreated with high concentrations of potassium chloride $(\mathrm{KCl})$ for $1 \mathrm{~h}$ prior to $S$. aureus stimulation for $4 \mathrm{~h}$. In MAC- $\mathrm{T}$ cells pretreated with $\mathrm{KCl}$, a dosedependent inhibition of $S$. aureus-mediated IL-1 $\beta$ and IL-18 release was observed. Moreover, caspase- 1 activity was observed (Figures 5E and F). S. aureus-induced secretion of the pro-inflammatory cytokines IL-1 $\beta$ and IL-18 by MAC-T cells depended on NLRP3 inflammasome activation.

\section{Discussion}

Bovine mastitis triggered by $S$. aureus infection remains a major problem in the dairy industry worldwide due to its pathogenicity, infectivity, colonization of skin or mucosal 


\section{A}

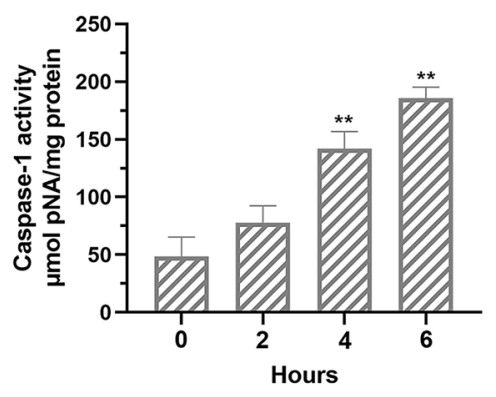

D

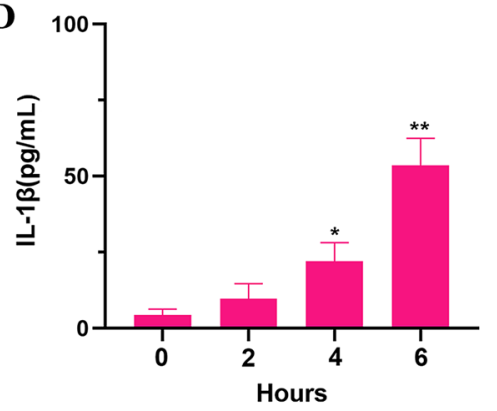

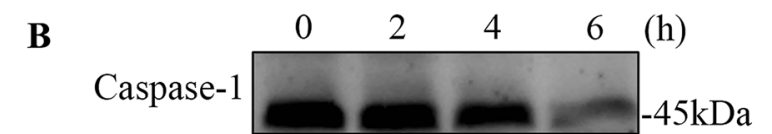

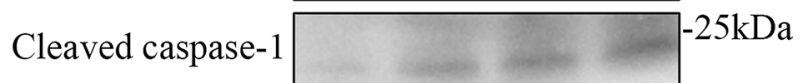

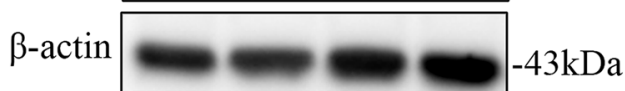

(h)

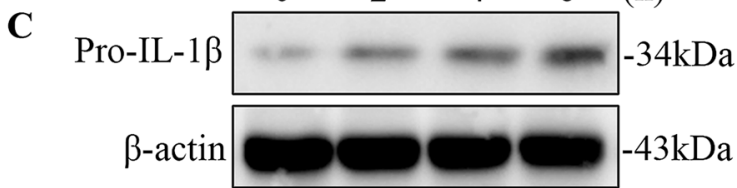

$\mathbf{E}$

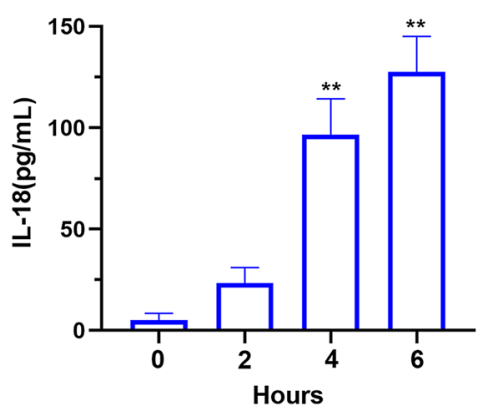

Figure 3 Caspase-1 and cytokine activation by S. aureus. A Detection of activated caspase-1 in MAC-T cells treated with S. aureus for the indicated times. B Cleaved caspase-1 and C pro-IL-1 $\beta$ were detected by immunoblotting. D Time course of IL-1 $\beta$ and IL-18 production by MAC-T cells treated with S. aureus.

epithelium, persistence in the dairy environment, and poor therapeutic efficacy $[19,20]$. Adhesion and invasion of bovine mammary epithelial cells are important factors in the formation of chronic infections [3]. Staphylococcus aureus can be ingested by bovine mammary epithelial cells, and intracellular $S$. aureus can escape endosomes and induce inflammation and cell death [21, 22]. Investigating the pyroptosis of MAC-T cells triggered by $S$. aureus contributes to the elucidation of the molecular basis of $S$. aureus mastitis pathogenesis.

Although apoptosis is the major form of regulated cell death, it is by no means the only form. A previous study described types of regulated cell death, including pyroptosis, necroptosis, and ferroptosis [23]. Pyroptosis, as an innate immune response to intracellular pathogens, is executed by caspase dependent cleavage of GSDMD [24]. In addition to caspase-1, caspase- 11 can also mediate pyroptosis. Caspase-11 is caspase- 1 independent and is activated by direct sensing of intracytoplasmic LPS [25]. In GSDMD-deficient cells, inflammasome stimulation induces apoptosis with the concomitant activation of caspase-3, which is largely caspase-1 dependent [26]. Inflammasomes are intracellular supramolecular complexes composed of a sensor molecule, ASC, and the effector caspase-1. When inflammasome sensor molecules are activated, ASC self-associates into helical fibrous assemblies, leading to the formation of the ASC speck [27]. The ASC speck acts as a molecular platform for the activation of procaspase-1. The NLRP3 inflammasome is a cytosolic signaling complex that mediates the activation of inflammatory mediators and can be activated by many danger signals closely associated with the pathogenesis of many common diseases [28-30]. Intracellular pathogens can activate NLRP3 inflammasome, causing the activation of inflammatory caspase-1, which in turn cleaves the proinflammatory cytokines IL- $1 \beta$ and IL-18, leading to their maturation. The activated caspases- 1 can cleave GSDMD into GSDMD-N and form pores in the plasma membrane through the aggregation of GSDMD-N fragments [31]. During pyroptosis, the GSDMD-N fragment permeabilizes the plasma membrane, leading to the release of IL-1 $\beta$, IL-18, and LDH [5]. LDH is a cytosolic enzyme that is released into the culture medium when membrane integrity is lost [32]. Some factors that contribute to NLRP3 activation are $\mathrm{K}^{+}$efflux, ROS production, lysosomal destabilization, and rupture [33-35]. 


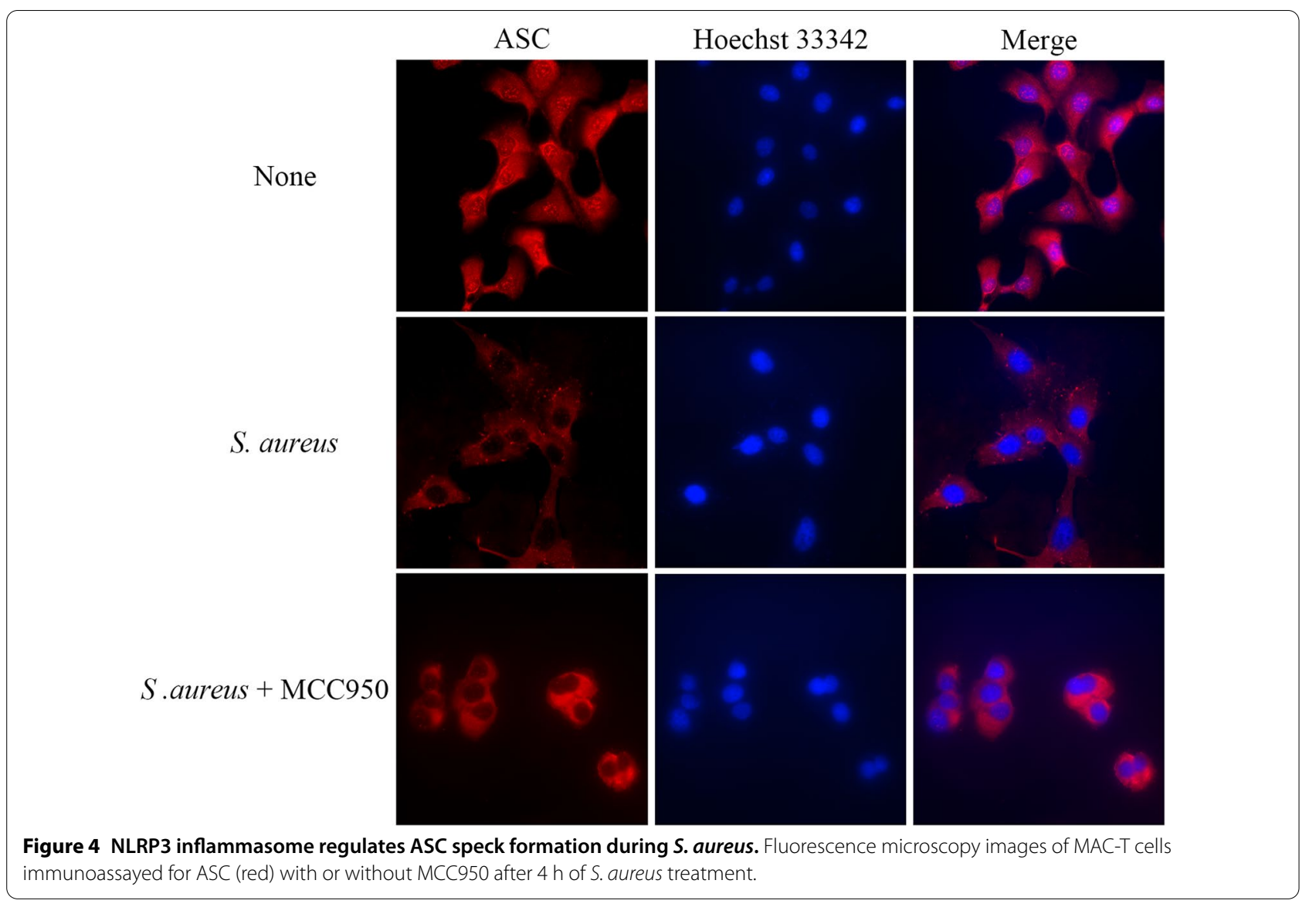

Staphylococcus aureus mastitis is an inflammatory reaction of the mammary gland that causes damage to mammary tissue and epithelial cells, which further results in reduced milk synthesis and secretion [36]. Staphylococcus aureus can invade within bovine mammary epithelial cells and multiply before causing cell death, which aid in the establishment of recurrent subclinical infections [37]. NLRP3 inflammasome is an important signaling pathway of the innate immune system and is essential for host defense against bacterial infection [38]. Pyroptosis induced by bacteria through the activation of NLRP3 inflammasome causes rupture of the cell membrane and the release of cytokines, which leads to the release of intracellular bacteria and the recruitment of inflammatory cells [39]. Thus, pyroptosis in bovine mammary epithelial cells is instrumental for replication niche deprivation and clearance of $S$. aureus later in infection. However, inappropriate or excessive activation of pyroptosis in epithelial cells can also lead to tissue damage [40].
Pyroptosis as a double-edged sword that plays a critical role in antibacterial defense and tissue damage. In this study, we developed a GSDMD-N antibody that can be used to detect bovine species and demonstrated that $S$. aureus is sensed by the NLRP3 inflammasome in MAC-T cells. Similar to previous studies, this process could be blocked by the inhibition of $\mathrm{K}^{+}$efflux [41]. Our data suggested that upon NLRP3 activation by $S$. aureus, ASC is recruited, and specks are formed, subsequently leading to the cleavage of caspase- 1 . Activated caspase- 1 cleaves pro-inflammatory cytokines IL-1 $\beta$, IL-18, and GSDMD. The generation of GSDMD$\mathrm{N}$ allows it to oligomerize and translocate to the plasma membrane, thereby inducing cell rupture and the release of IL- $1 \beta$ and IL-18.

Staphylococcus aureus can activate NLRP3 and cause MAC-T cell pyroptosis via the $\mathrm{K}^{+}$efflux pathway. Our work provides insight into the potential role of NLRP3 in the molecular pathogenesis of $S$. aureus mastitis and contributes to the elucidation of the molecular basis of $S$. aureus mastitis pathogenesis. 
A

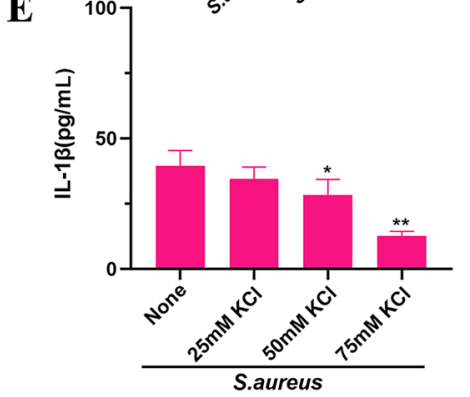

B

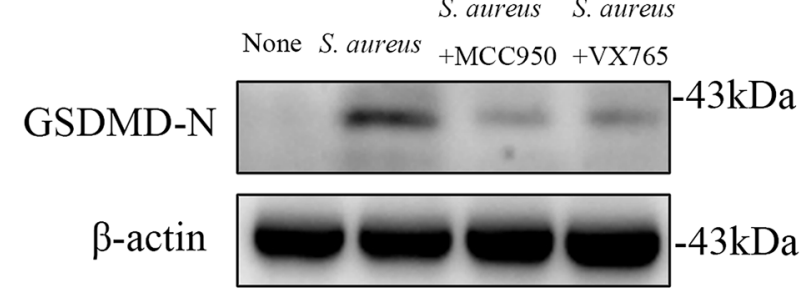

D

$\mathbf{F}$

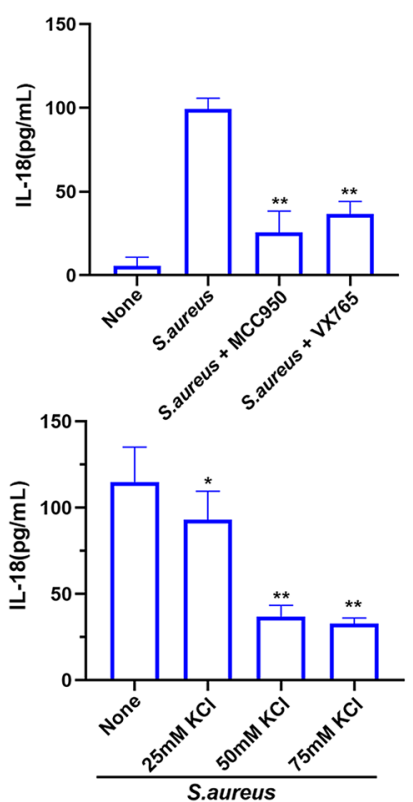

Figure 5 NLRP3 inflammasome activation by S. aureus is essential for the generation of GSDMD-N and the release of IL-1 $\beta$ and IL-18. A Activated caspase- 1 and $\mathbf{B}$ GSDMD-N or released $\mathbf{C} I L-1 \beta$ and $\mathbf{D}$ IL-18 of MAC-T cells treated with or without NLRP3 inhibitor MCC950 or caspase-1 inhibitor VX765 for $1.5 \mathrm{~h}$ prior to treatment with S. aureus for $4 \mathrm{~h}$. E Levels of IL-1 $\beta$ and $\mathbf{F} \mathrm{IL}-18$ released after $\mathrm{S}$. aureus treatment of MAC-T cells for $4 \mathrm{~h}$ in the presence or absence of 25,50 , or $75 \mathrm{mM} \mathrm{KCl}$.

\section{Abbreviations}

S. aureus: Staphylococcus aureus; MAC-T: a cell line produced from primary bovine mammary alveolar cells by stable transfection with SV-40 large T-antigen; NLRP3: NOD-like receptor protein 3; ASC: apoptosis-associated speck-like protein; GSDMD: gasdermin D; LB: Luria-Bertani; DMEM: Dulbecco's modified Eagle medium; FBS: fetal bovine serum; Ac-YVAD-pNA: Acetyl-Tyr-Val-Ala-Asp p-nitroanilide; pNA: p-Nitroanilide; MOI: multiplicity of infection; PI: propidium iodide; PS: phospholipid phosphatidylserine.

\section{Supplementary Information}

The online version contains supplementary material available at https://doi. org/10.1186/s13567-022-01027-y.

Additional file 1. Peptide sequence used for antibody preparation.

\section{Acknowledgements}

The project was supported by the National Natural Science Foundation of China (31802259, 31872535), Shandong Key R\&D Program (2019GNC106141), Shandong Natural Science Foundation of China (ZR2018MC027), China Postdoctoral Science Foundation (2018M632704, 2019T120601), and Funds of Shandong "Double Tops" Program.

\section{Authors' contributions}

Conceptualization, YL and BH; Data curation, XW and NG; Formal analysis, ML; Funding acquisition, YL; Investigation, XW; Methodology, XW and YD; Project administration, $J L$ and $Y L$; Resources, $X W$ and NG; Software, ML; Supervision, $J \mathrm{~L}$ and $\mathrm{YL}$; Validation, ZL and $\mathrm{YL}$; Visualization, $X \mathrm{G}$; Writing —original draft, $X W$; Writing - review and editing, YL and JL. All authors read and approved the final manuscript.

\section{Declarations}

\section{Competing interests}

The authors declare that they have no competing interests.

\section{Author details}

${ }^{1}$ College of Veterinary Medicine, Shandong Agricultural University, Tai'an 271018, Shandong, China. ${ }^{2}$ College of Veterinary Medicine, Hebei Agricultural University, Baoding 071001, Hebei, China. ${ }^{3}$ Research Center for Animal Disease Control Engineering, Shandong Agricultural University, Tai'an 271018, Shandong, China. ${ }^{4}$ College of Veterinary Medicine, China Agricultural University, Beijing 100193, China.

Received: 10 November 2021 Accepted: 10 January 2022

Published online: 05 February 2022 


\section{References}

1. Barkema HW, Schukken YH, Zadoks RN (2006) Invited review: the role of cow, pathogen, and treatment regimen in the therapeutic success of bovine Staphylococcus aureus mastitis. J Dairy Sci 89:1877-1895

2. Peton V, Le Loir Y (2014) Staphylococcus aureus in veterinary medicine. Infect Genet Evol 21:602-615

3. Kerro Dego O, van Dijk JE, Nederbragt H (2002) Factors involved in the early pathogenesis of bovine Staphylococcus aureus mastitis with emphasis on bacterial adhesion and invasion. A review. Vet Q 24:181-198

4. Lahouassa H, Moussay E, Rainard P, Riollet C (2007) Differential cytokine and chemokine responses of bovine mammary epithelial cells to Staphylococcus aureus and Escherichia coli. Cytokine 38:12-21

5. Man SM, Karki R, Kanneganti TD (2017) Molecular mechanisms and functions of pyroptosis, inflammatory caspases and inflammasomes in infectious diseases. Immunol Rev 277:61-75

6. Shi J, Zhao Y, Wang K, Shi X, Wang Y, Huang H, Zhuang Y, Cai T, Wang F, Shao $F$ (2015) Cleavage of GSDMD by inflammatory caspases determines pyroptotic cell death. Nature 526:660-665

7. Kesavardhana S, Malireddi RKS, Kanneganti TD (2020) Caspases in cell death, inflammation, and pyroptosis. Annu Rev Immunol 38:567-595

8. Jorgensen I, Miao EA (2015) Pyroptotic cell death defends against intracellular pathogens. Immunol Rev 265:130-142

9. Jorgensen I, Rayamajhi M, Miao EA (2017) Programmed cell death as a defence against infection. Nat Rev Immunol 17:151-164

10. Elliott El, Sutterwala FS (2015) Initiation and perpetuation of NLRP3 inflammasome activation and assembly. Immunol Rev 265:35-52

11. Fernandes-Alnemri T, Wu J, Yu JW, Datta P, Miller B, Jankowski W, Rosenberg S, Zhang J, Alnemri ES (2007) The pyroptosome: a supramolecular assembly of ASC dimers mediating inflammatory cell death via caspase-1 activation. Cell Death Differ 14:1590-1604

12. Boucher D, Monteleone M, Coll RC, Chen KW, Ross CM, Teo JL, Gomez GA, Holley CL, Bierschenk D, Stacey KJ, Yap AS, Bezbradica JS, Schroder $\mathrm{K}$ (2018) Caspase-1 self-cleavage is an intrinsic mechanism to terminate inflammasome activity. J Exp Med 215:827-840

13. Shi J, Gao W, Shao F (2017) Pyroptosis: gasdermin-mediated programmed necrotic cell death. Trends Biochem Sci 42:245-254

14. Broz P, Pelegrin P, Shao F (2020) The gasdermins, a protein family executing cell death and inflammation. Nat Rev Immunol 20:143-157

15. Wang $K$, Sun $Q$, Zhong X, Zeng M, Zeng H, Shi X, Li Z, Wang Y, Zhao Q, Shao F, Ding J (2020) Structural mechanism for GSDMD targeting by autoprocessed caspases in pyroptosis. Cell 180:941-955.e920

16. Frank D, Vince JE (2019) Pyroptosis versus necroptosis: similarities, differences, and crosstalk. Cell Death Differ 26:99-114

17. Wang Y, Gao W, Shi X, Ding J, Liu W, He H, Wang K, Shao F (2017) Chemotherapy drugs induce pyroptosis through caspase-3 cleavage of a gasdermin. Nature 547:99-103

18. Orning P, Lien E, Fitzgerald KA (2019) Gasdermins and their role in immunity and inflammation. J Exp Med 216:2453-2465

19. Anderson KL, Lyman R, Moury K, Ray D, Watson DW, Correa MT (2012) Molecular epidemiology of Staphylococcus aureus mastitis in dairy heifers. J Dairy Sci 95:4921-4930

20. Middleton JR, Luby CD, Adams DS (2009) Efficacy of vaccination against staphylococcal mastitis: a review and new data. Vet Microbiol 134:192-198

21. Bayles KW, Wesson CA, Liou LE, Fox LK, Bohach GA, Trumble WR (1998) Intracellular Staphylococcus aureus escapes the endosome and induces apoptosis in epithelial cells. Infect Immun 66:336-342

22. Gunther J, Esch K, Poschadel N, Petzl W, Zerbe H, Mitterhuemer S, Blum H, Seyfert HM (2011) Comparative kinetics of Escherichia coli- and Staphylococcus aureus-specific activation of key immune pathways in mammary epithelial cells demonstrates that $S$. aureus elicits a delayed response dominated by interleukin-6 (IL-6) but not by IL-1A or tumor necrosis factor alpha. Infect Immun 79:695-707

23. Tang D, Kang R, Berghe TV, Vandenabeele P, Kroemer G (2019) The molecular machinery of regulated cell death. Cell Res 29:347-364

24. Liu X, Zhang Z, Ruan J, Pan Y, Magupalli VG, Wu H, Lieberman J (2016) Inflammasome-activated gasdermin D causes pyroptosis by forming membrane pores. Nature 535:153-158

25. Kayagaki N, Stowe IB, Lee BL, O'Rourke K, Anderson K, Warming S, Cuellar T, Haley B, Roose-Girma M, Phung QT, Liu PS, Lill JR, Li H, Wu J, Kummerfeld S, Zhang J, Lee WP, Snipas SJ, Salvesen GS, Morris LX, Fitzgerald
L, Zhang Y, Bertram EM, Goodnow CC, Dixit VM (2015) Caspase-11 cleaves gasdermin D for non-canonical inflammasome signalling. Nature 526:666-671

26. Tsuchiya K, Nakajima S, Hosojima S, Thi Nguyen D, Hattori T, Le Manh T, Hori O, Mahib MR, Yamaguchi Y, Miura M, Kinoshita T, Kushiyama H, Sakurai M, Shiroishi T, Suda T (2019) Caspase-1 initiates apoptosis in the absence of gasdermin D. Nat Commun 10:2091

27. Stutz A, Horvath GL, Monks BG, Latz E (2013) ASC speck formation as a readout for inflammasome activation. Methods Mol Biol 1040:91-101

28. Prochnicki T, Latz E (2017) Inflammasomes on the crossroads of innate immune recognition and metabolic control. Cell Metab 26:71-93

29. Haneklaus M, O'Neill LA (2015) NLRP3 at the interface of metabolism and inflammation. Immunol Rev 265:53-62

30. Li Z, Guo J, Bi L (2020) Role of the NLRP3 inflammasome in autoimmune diseases. Biomed Pharmacother 130:110542

31. Ding J, Wang K, Liu W, She Y, Sun Q, Shi J, Sun H, Wang DC, Shao F (2016) Pore-forming activity and structural autoinhibition of the gasdermin family. Nature 535:111-116

32. Koh JY, Choi DW (1987) Quantitative determination of glutamate mediated cortical neuronal injury in cell culture by lactate dehydrogenase efflux assay. J Neurosci Methods 20:83-90

33. Petrilli V, Papin S, Dostert C, Mayor A, Martinon F, Tschopp J (2007) Activation of the NALP3 inflammasome is triggered by low intracellular potassium concentration. Cell Death Differ 14:1583-1589

34. Gurung P, Lukens JR, Kanneganti TD (2015) Mitochondria: diversity in the regulation of the NLRP3 inflammasome. Trends Mol Med 21:193-201

35. Campden Rl, Zhang Y (2019) The role of lysosomal cysteine cathepsins in NLRP3 inflammasome activation. Arch Biochem Biophys 670:32-42

36. Zhao X, Lacasse P (2008) Mammary tissue damage during bovine mastitis: causes and control. J Anim Sci 86:57-65

37. Zaatout N, Ayachi A, Kecha M (2020) Staphylococcus aureus persistence properties associated with bovine mastitis and alternative therapeutic modalities. J Appl Microbiol 129:1102-1119

38. Vladimer Gl, Marty-Roix R, Ghosh S, Weng D, Lien E (2013) Inflammasomes and host defenses against bacterial infections. Curr Opin Microbiol 16:23-31

39. LaRock CN, Cookson BT (2013) Burning down the house: cellular actions during pyroptosis. PLoS Pathog 9:e1003793

40. Churchill MJ, Mitchell PS, Rauch I (2021) Epithelial pyroptosis in host defense. J Mol Biol 2021:167278

41. Munoz-Planillo R, Kuffa P, Martinez-Colon G, Smith BL, Rajendiran TM, Nunez G (2013) $\mathrm{K}^{+}$efflux is the common trigger of NLRP3 inflammasome activation by bacterial toxins and particulate matter. Immunity 38:1142-1153

\section{Publisher's Note}

Springer Nature remains neutral with regard to jurisdictional claims in published maps and institutional affiliations.
Ready to submit your research? Choose BMC and benefit from:

- fast, convenient online submission

- thorough peer review by experienced researchers in your field

- rapid publication on acceptance

- support for research data, including large and complex data types

- gold Open Access which fosters wider collaboration and increased citations

- maximum visibility for your research: over 100M website views per year

At BMC, research is always in progress.

Learn more biomedcentral.com/submissions 